\title{
Building Indigenous Girl Networks in South Dakota
}

Kelly Hallman

Population Council

Stephanie Martinez

Follow this and additional works at: https://knowledgecommons.popcouncil.org/departments_sbsr-pgy How does access to this work benefit you? Let us know!

\section{Recommended Citation}

Hallman, Kelly and Stephanie Martinez. 2019. "Building Indigenous Girl Networks in South Dakota," IMAGEN Brief no. 3. New York: Indigenous Adolescent Girls' Empowerment Network (IMAGEN). 


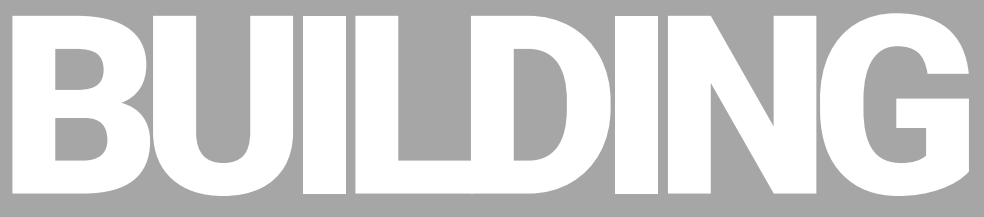

One organization's journey

to illuminate and support

INDIGENOUS GIRL

its local universe of

adolescent girls

NETWORKS IN

SOUTHDAKOTA

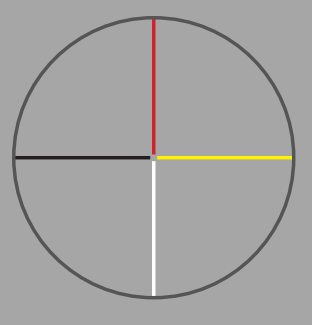

\section{AN ORGANIZATION, A MISSION}

The White Buffalo Calf Women's Society (WBCWS) serves the Sicangu Oyate, also known as the Sicangu Lakota and the Rosebud Sioux Tribe, on the Rosebud Reservation in South Dakota. Building off of the work of their founding Lakota grandmothers, the staff at WBCWS serves community members who have been victims of domestic violence, sexual assault, dating violence, and stalking by providing safe shelter and services. The organization centers itself on the teachings of Pte' San Win, the White Buffalo Calf Woman, who is an important Lakota figure connected to purification, female adolescence, and womanhood. WBCWS was the first women's shelter on an Indian Reservation in the U.S., and continues to play an important role on the Rosebud Reservation.

In 2017, WBCWS began its partnership with the Indigenous Adolescent Girls' Empowerment Network (IMAGEN). IMAGEN, based at the groundbreaking GIRL Center in New York City, is part of a global initiative designed to build national networks of organizations that adapt, build, and share innovative skills and tools that strategically serve the needs of adolescent girls. The foundations of the GIRL Center and IMAGEN are built off of decades of programmatic research on girls, their communities, their agency, and the unique ways in which they become vulnerable at different stages of their lives. Based in the U.S., IMAGEN brings organizations together to propose ways to create local networks of female kinship and power that reclaim the strong traditions of female leadership that were erased through colonization. The network held its first meeting in 2017 with local and national indigenous organizations to begin a conversation on the programmatic gaps and opportunities that exist for girl-centered programming in Indian country.

\section{GLOBALLY, we know that:}

- The physical world of a girl shrinks after puberty

- Girls tend to have many more life-changing "transitions" as teenagers than do boys

- A large percentage of adolescent girls will become single mothers

\section{LOCALLY, we know that:}

- 1 in 3 Indian women report having been sexually assaulted in her lifetime (often by non-Native attackers)

- Native females have fewer financial assets and skills than Native males

- Native girls may face high risks of trafficking

- The highest rate of teen births nationwide are found among Native girls, at a rate of 11.3 per 1,000 
In this activity, participants placed asset cards under the age category by which they believed a girl should be able to accomplish it. Participants were also encouraged to create additional asset cards, such as the blue one shown here, with culturally specific skills they would want to see.

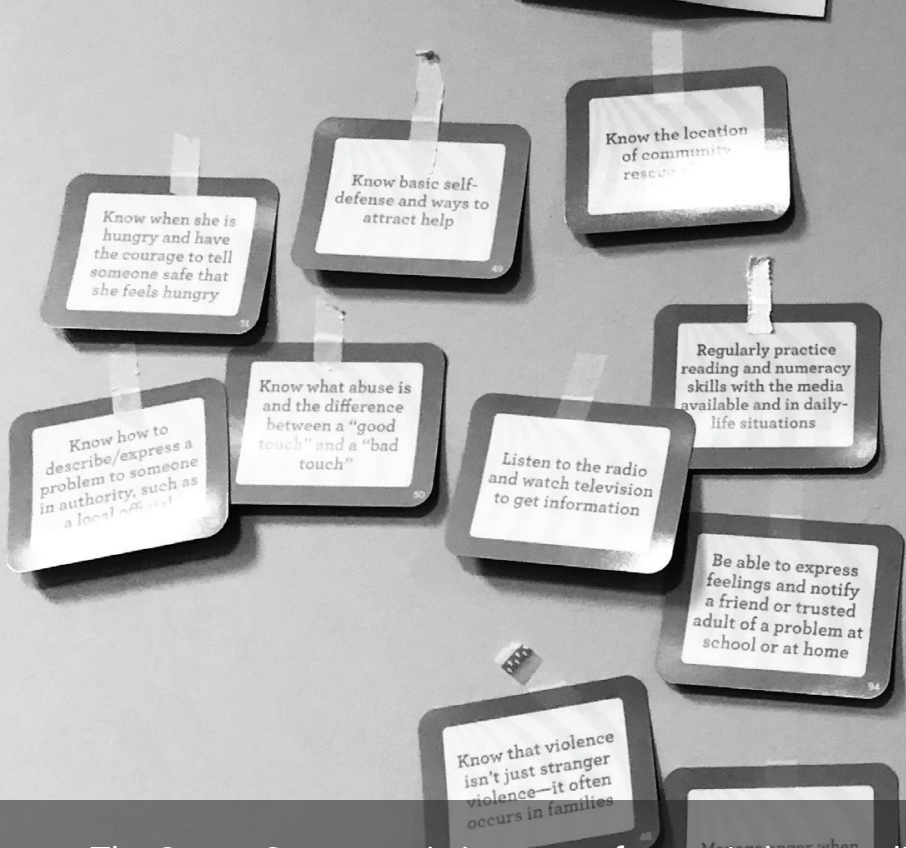

The Sweat Ceremony is just one of many Lakota traditions that WBCWS encourages as a way to cleanse, heal, and strengthen Lakota identity. The teaching and promotion of Lakota tradition is a key part of the Wicincila Society curriculum as well.

\section{A COLLABORATION IN GIRL-CENTERED PROGRAMMING}

WBCWS took the lead in becoming the first group to pilot the tools and program ideas available through IMAGEN in their local community.

Over the course of two years and with the technical assistance of subject matter experts on girl-centered programming at the GIRL Center, WBCWS created the Wicincila Society. Sustainably integrated with and framed as a means to support WBCWS' domestic violence prevention initiative programming, the Wicincila Society designed a network of female mentorship for adolescent girls throughout pilot communities on the Rosebud reservation (Rosebud, St. Francis, Parmalee, Antelope, and Ideal).

After trained WBCWS staff members built and used a Youth Roster to enumerate the local universe of girls and their unique vulnerabilities on the reservation, the Wicincila Society and IMAGEN created a curriculum to build capacity among local adolescent girls by integrating life skills lessons and activities with teachings on Lakota traditions and kinship. Example topics in the curriculum include:

- Self-Confidence

- Nutrition \& Hygiene

- The Creation Story

- Sexual and Reproductive Health

- Traditional Dress and Belt-making

- Healthy Relationships

\section{A FUTURE FOR GIRLS}

As the Wicincila Society currently wraps up its mentor training, it is simultaneously building its next phase of programs by networking with community leaders to secure the regular meeting areas and social investments needed to provide the girls with a safe and respected space. IMAGEN will continue to collaborate with and provide monitoring guidance to the Wicincila Society as it moves forward in building a future in which girls thrive on the Rosebud Reservation and beyond. 
In one technical assistance activity, local program leaders identified key assets and monitoring strategies needed for each age group in their girl-centered programming.
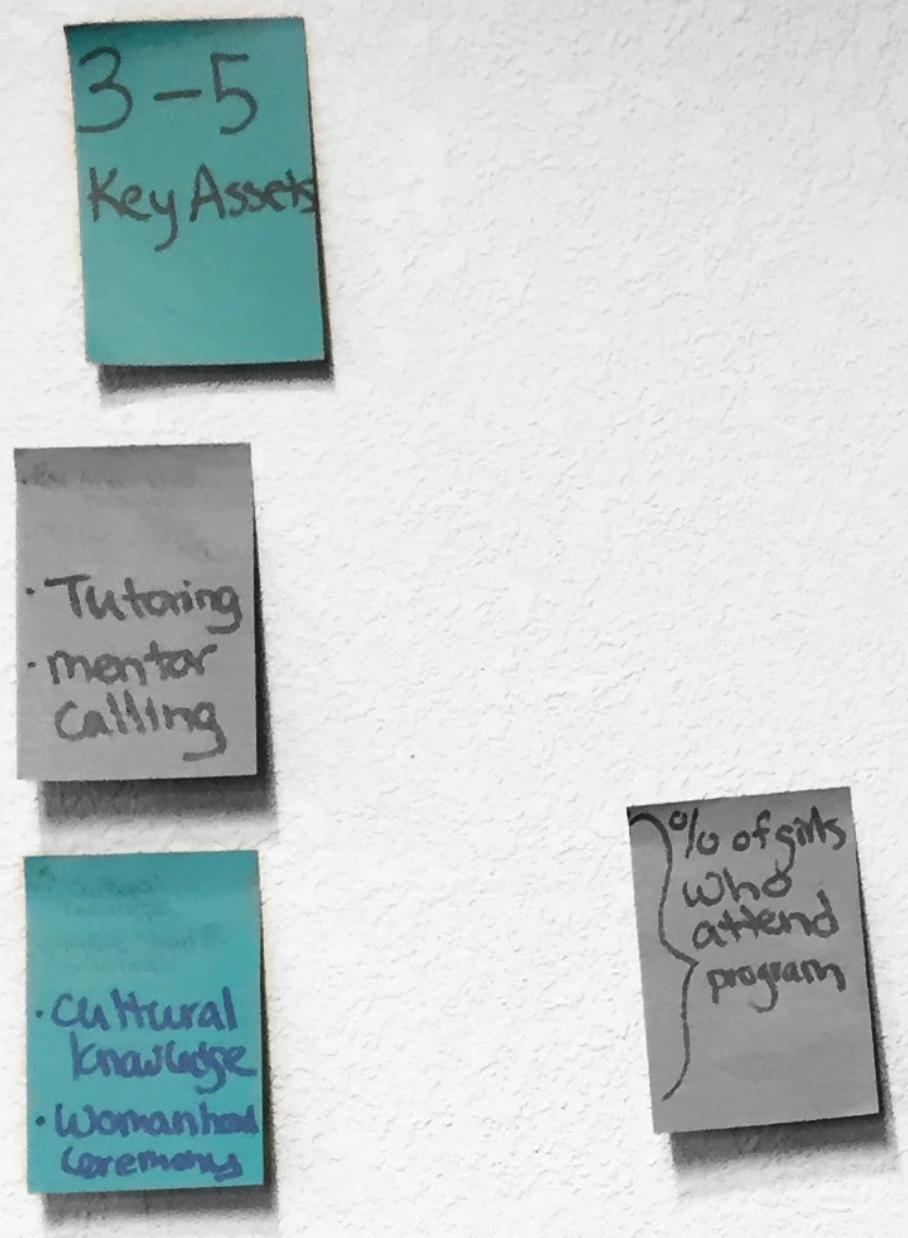
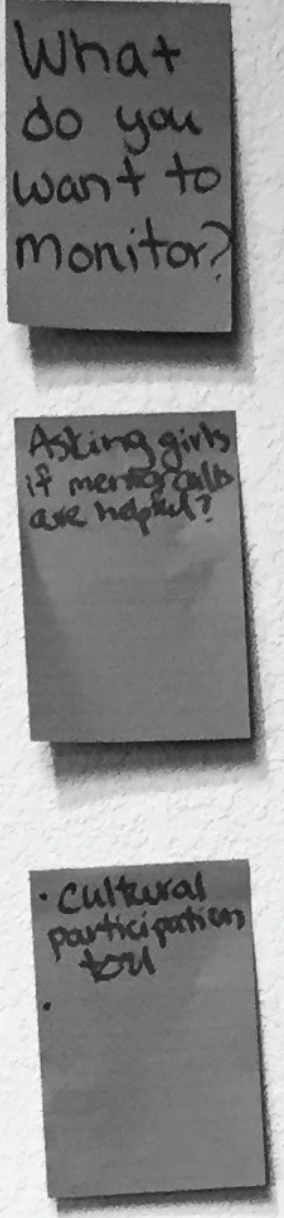
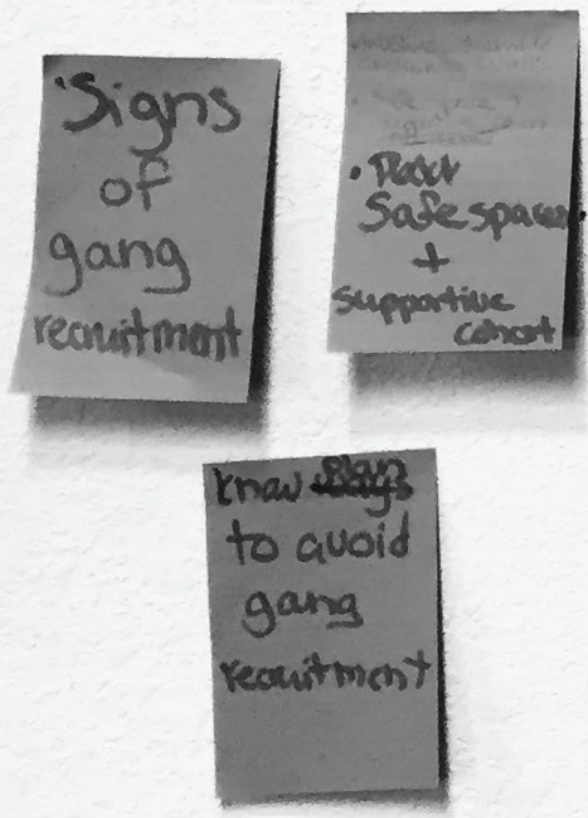

\section{Learn more about our work www.imagen-network.org}

\section{GIRL Center}

FOR GIRL INNOVATION, RESEARCH, AND LEARNING

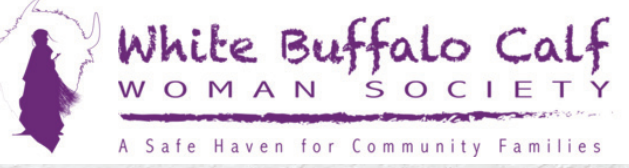

\section{Suggested Citation}

Hallman K., Martinez S. 2019. Building Indigenous Girl Networks in South Dakota. NY, NY. Indigenous Adolescent Girls' Empowerment Network (IMAGEN). 